\title{
A review of the pathology and pathogenesis of acute renal failure due to acute tubular necrosis
}

\author{
M. S. DUNNILL \\ From the Gibson Laboratories, Radcliffe Infirmary, Oxford
}

Renal failure may present as anuria or oliguria. This may result from postrenal causes such as urinary obstruction due to stone or tumour, or from acute glomerular disease, but one common cause of acute oliguric renal failure is the group of conditions known as 'acute tubular necrosis'. These follow a period of shock or haemorrhage resulting in renal ischaemia or may be due to direct renal poisons. The clinical features and the pathology of the condition vary only slightly with the aetiology. Although spontaneous recovery occurs in many instances, the mortality is still considerable and Kennedy, Burton, Luke, Briggs, Lindsay, Allison, Edward, and Dargie (1973) in surveying 250 cases found a mortality of $44 \%$.

\section{Aetiology}

The two main categories of aetiological agent, namely, the nephrotoxic and the ischaemic, frequently overlap. Thus in states such as mismatched transfusion there is a combination of shock and a possible toxic effect of the free haemoglobin as well as immunological damage from the altered red cell stroma (Schmidt and Holland, 1967). The distinction between the two main factors in the aetiology of tubular necrosis may be important when the mechanism of the renal disturbances is considered. The hypotensive situations result in a greatly diminished renal blood flow and glomerular filtration rate together with possible glomerular damage. The toxic conditions result in damage to specific portions of the renal tubule.

Interest in this condition is always intensified during time of war when extensive limb damage and crush injuries are more frequent than in peace. However, minor or major degrees of renal functional impairment are common after surgical operations, haemorrhage from any cause, and self-poisoning as well as the road accidents and burns seen all too

Received for publication 5 October 1973. often in civilian life. Obstetric haemorrhage, particularly when following preeclampsia, is an increasingly uncommon but still important cause of $\vec{\sim}$ the syndrome. Renal cortical necrosis is a distinct $\subseteq$ disease syndrome which is not considered here. The table gives a brief list of the most frequent causes of the syndrome of acute renal failure associated with tubular necrosis.

\begin{tabular}{ll}
\hline I & Traumatic shock associated with hypotension \\
& Burns \\
& Crush injuries \\
II & Postoperative shock and surgical trauma \\
III & Obstetric shock, abortion \\
IV & Septicaemia \\
V & Acute peritonitis, acute pancreatitis \\
VI & Poisons, 'nephrotoxins' \\
& Eg, \\
& Inorganic and organic mercury compounds \\
& Carbon tetrachloride \\
& Ethylene glycol \\
& Neomycin \\
VII & Conditions causing acute haemoglobinuria \\
& Eg, Mismatched blood transfusion \\
& Blackwater fever
\end{tabular}

Table Some causes of renal failure due to 'acute tubular necrosis'

\section{Clinical Features}

The term anuria means literally the failure to form any urine but in practice clinicians use the term loosely to embrace an output of less than $100 \mathrm{ml}$ in 24 hours (Hamburger, Richet, Crosnier, FunckBrentano, Antoine, Ducrot, Mery, and de Montera, 1968). Oliguria, indicating a reduced output of urine of, say, less than $500 \mathrm{ml}$ over a 24-hour period with a normal fluid intake, is a fairly constant but not invariable feature of the syndrome. Teschan, Post, Smith, Abernathy, Davis, Gray, Howard, Johnson, Klopp, Mundy, O'Meara, and Rush (1955) and Sevitt (1959) have drawn attention to some forms of uraemia associated with burns in which the urinary output was normal or even increased.

Four clinical phases are described. 


\section{FIRST PHASE}

The first phase usually only lasts between one and 10 hours and extends from the time of the initial insult until the onset of oliguria.

\section{ANURIC PHASE}

The 'anuric' phase may last for a variable time being as short as two or three days in many postoperative surgical cases or as long as 28 days in severe cases of burns or obstetric shock. The urinary output falls drastically but rarely is there true anuria. If the intake of fluid is not restricted the total body water increases. This may result in the serum sodium and chloride undergoing an apparent fall. Due to the anuria, frequently augmented by tissue destruction in conditions such as burns, the serum potassium rises. The urine is of low specific gravity, often dark, and the ratio of urinary urea to plasma urea is reduced, all of which points to depressed tubular function. Proteinuria is usually absent or slight. The urinary sodium and chloride are not unduly depressed and the sodium value is often greater than 30 m-equiv per litre.

\section{PHASE OF DIURESIS}

The third phase is one of diuresis and this may last from two to 14 days. The urine resembles glomerular filtrate and there may be a considerable electrolyte loss.

\section{RECOVERY PHASE}

The recovery phase starts gradually with the urine becoming more concentrated as tubular function returns. An apparent clinical recovery is usual but Briggs, Kennedy, Young, Luke, and Gray (1967) in studying renal function in 50 patients four to 75 weeks after a well documented episode of acute tubular necrosis showed an abnormality of function to be present in $74 \%$ with a lowered glomerular filtration rate in $71 \%$ and an impaired urine concentration test in $31 \%$.

\section{Pathology}

The appearances of the kidney at necropsy in the first two or three days after injury are not distinctive and show only an increase in size with bulging of the cut surface due to marked oedema and some cortical pallor with congestion of the medulla (fig 1). The capsule strips easily leaving a smooth surface. After four days there is often a characteristic zone of pallor at the corticomedullary junction (Bywaters and Dible, 1942). If the patient dies following a long period of renal dialysis, the kidney may have returned to a normal size and may even show some interstitial fibrosis.

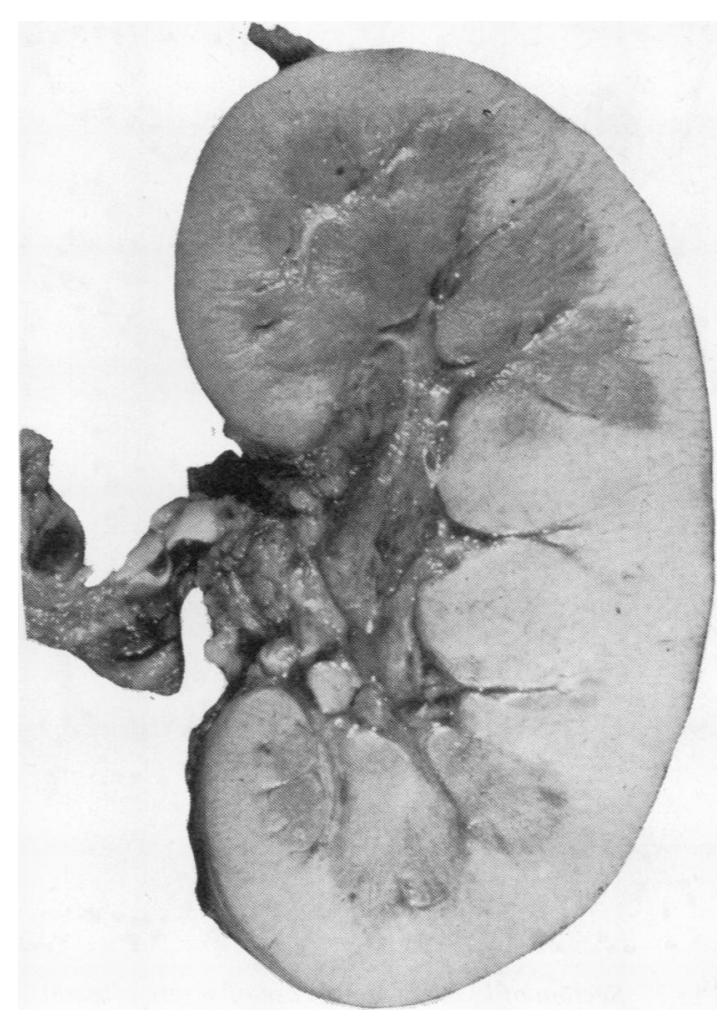

Fig 1 Kidney from an anuric child dying three days after $60 \%$ body burns.

\section{HISTOLOGY}

The microscopic appearances vary with the stage of the disease and to a certain extent with the underlying aetiological agent.

\section{Glomerular changes}

The glomeruli in many instances have been described as normal. Bywaters and Dible (1942) found the capillary tufts to be congested but there was no alteration in the capillary endothelium or basement membrane. They did note that the capsular space was filled with eosinophilic debris by the second day (fig 2). This debris took the form of lightly staining spherical masses of uncertain nature which they thought might possibly represent necrotic desquamated cellular material or a protein precipitate. They also drew attention to a metaplastic change in Bowman's capsule with the lining cells assuming a columnar shape similar to that seen in the proximal convoluted tubule. This metaplastic change has also been emphasized by Waugh, Schlieter, and James (1964) and by Heptinstall 


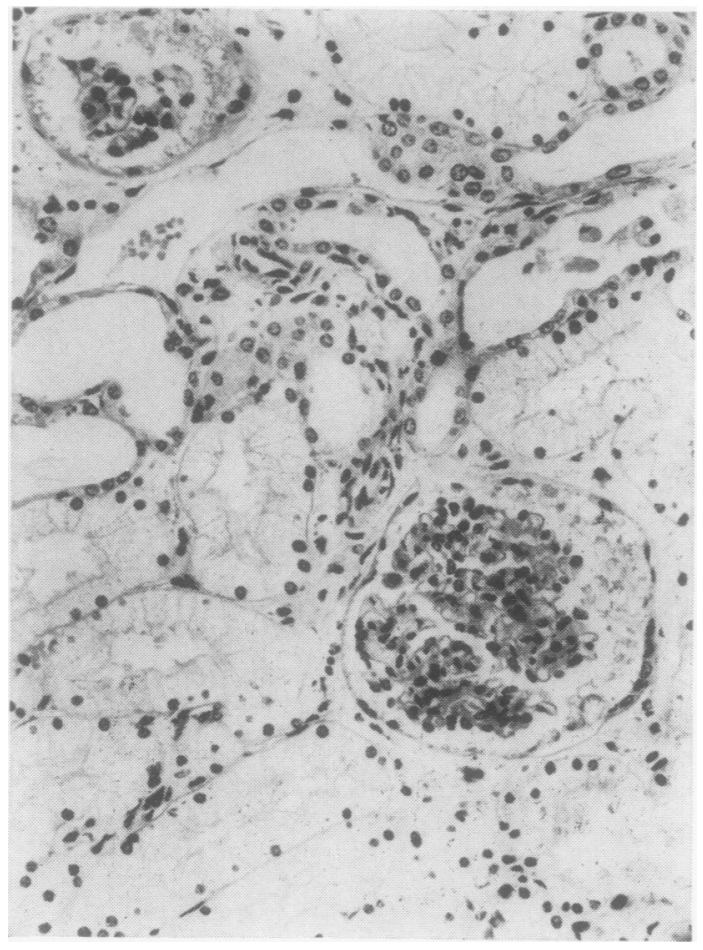

Fig 2 Section of kidney from a case of severe oliguria following burns showing (i) normal glomerular capillaries, (ii) debris in Bowman's space, (iii) hydropic change of the proximal tubular epithelium. There is some early focal necrosis present in the proximal tubular epithelium as some of the cells have no or indistinct nuclei. Haematoxylin and eosin $\times 90$.

(1966) who considered that it was due to reflux of the proximal tubular epithelium into Bowman's space. Hamburger et al (1968) found that in many instances the glomerular capillaries were collapsed but they drew attention to the occasional presence of intracapillary thrombi and also to the presence of protein in the urinary space.

\section{Electron microscope studies on the glomeruli}

Ultrastructural studies have been few and somewhat contradictory. Dalgaard (1960) and Dalgaard and Pedersen (1961) were unable to demonstrate any abnormality in the glomeruli in five cases of shock. Recently, however, Clarkson, MacDonald, Fuster, Cash, and Robson (1970) have claimed to show abnormalities in the glomerular capillaries by a careful electron microscope study of biopsy material taken during the oliguric phase. Deposits of fibrin and platelets consistent within traglomerular capillary thrombosis were found. The importance of these findings in the mechanism and course of the renal failure will be considered later. These findings which Clarkson et al (1970) describe are not in accord with those reported by Olsen and Skjoldborg (1967) who examined 12 biopsies from 10 patients and in general found the glomeruli to be normal although in two instances there was swelling of the epithelial cell cytoplasm and in one case a capillary lumen was occluded by swelling of endothelial and mesangial cells. Certainly in anuria following experimental acute tubular necrosis in the rat the glomeruli appear normal (fig 3).

\section{Tubular changes}

These are often the most dramatic and obvious lesions on light microscopy (figs 4 and 5). Classically $\vec{i}$ two main components are described, namely, the nephrotoxic lesion and tubulorrhexis (Dunn, Gillespie, and Niven, 1941; Oliver, MacDowell, and Tracy, 1951).

1 The nephrotoxic lesion affects primarily the proximal tubule and is seen at the beginning of the anuric stage. It varies from swelling of the cell cytoplasm with dissolution of mitochondria to complete necrosis with absence of nuclei. The site of the lesion may vary depending upon the aetiological agent: thus in potassium chromate poisoning the proximal third of the tubule is said to be involved, in potassium chlorate the middle third, and in mercuric chloride and ethylene glycol poisoning the terminal third of the tubule are affected. All the nephrons appear equally damaged and the tubular basement membrane is typically intact.

2 Tubulorrhexis is characterized by tubular rupture. It may be found in any part of the nephron and can be seen in the collecting as well as in the proximal and distal tubules but is said to be most frequent in the region of the cortico-medullary junction. It is distinctly focal in distribution, many nephrons being spared, and is thought to be ischaemic in origin. Casts containing pigment are a frequent finding.

In histological sections one of the most striking features, first mentioned by Brun and Munck (1957), is the impressive contrast between the moderate tubular structural change and the complete functional breakdown. In fact the clinico-pathological correlation with regard to the tubular lesions is notably poor. Lucké (1946) considered that in cases of shock and severe intravascular haemolysis the lesions were mainly in the distal tubule; hence the confusing term 'lower nephron nephrosis' found in the older literature. Many renal poisons, on the other hand, were thought to affect the proximal tubule only. These views were based on examination of conventional light microscope histological sections. 


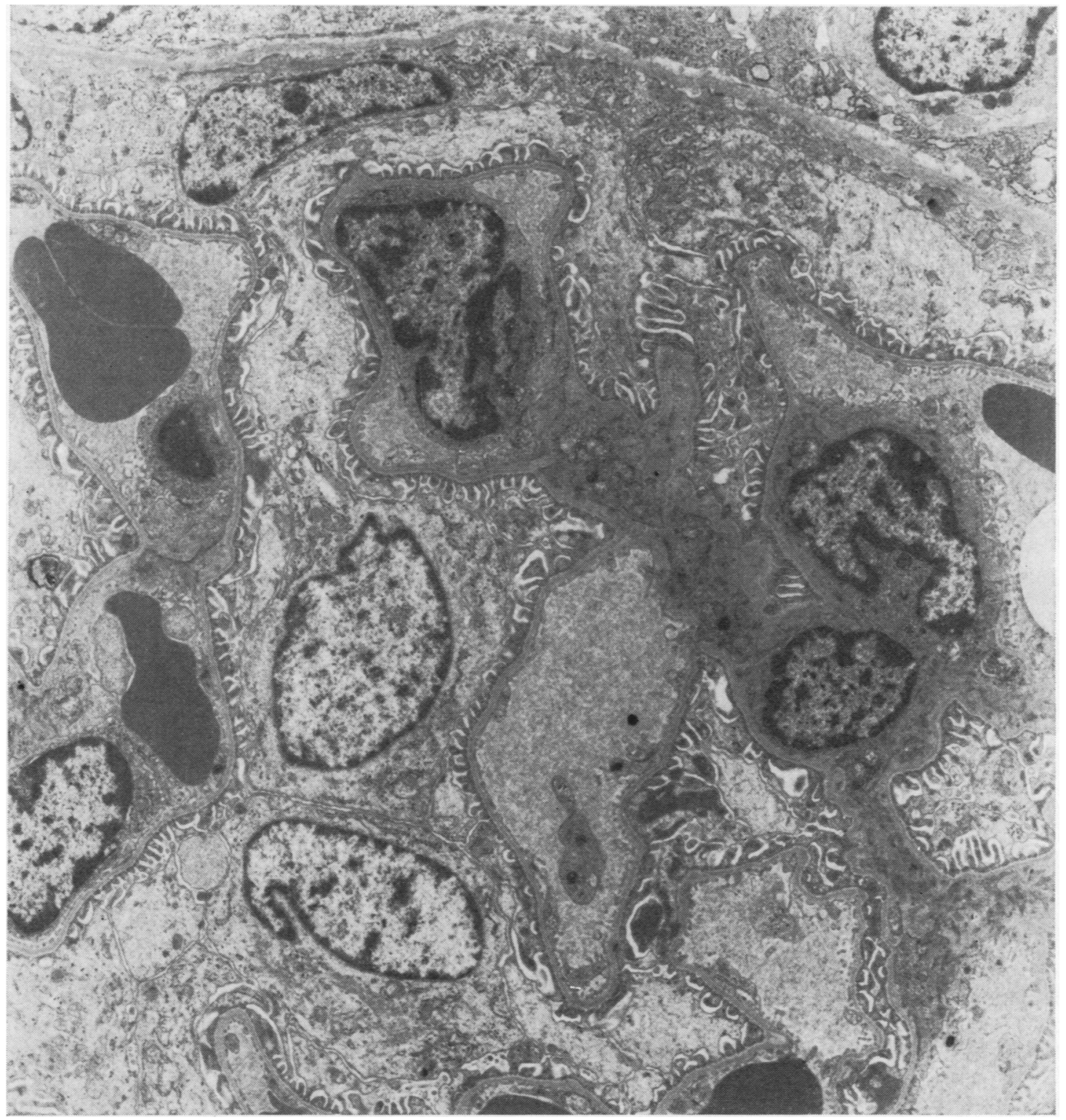

Fig 3 Electron micrograph of glomerulus from a rat suffering from anuria due to acute tubular necrosis two days following intramuscular mercuric chloride. The glomerulus has a normal architecture and no fibrin platelet aggregates can be seen. $\times 6000$.

Oliver et al (1951), using the method of microdissection, showed that the lesions of both types were often present and furthermore that they were patchy in distribution within any one nephron. In particular, Oliver demonstrated that tubulorrhexis occurred in the straight limb of the proximal tubule, often in the boundary zone between cortex and medulla. The two lesions occurred in acute renal failure from any cause in varying proportions depending on the nature of the renal insult whether toxic, circulatory, or both.

The proximal tubule when viewed in conventional 
Fig 4

Fig 5

Fig 4 Section from a male aged 57 years with anuria for seven days following a prolonged period of hypotension due to a myocardial infarct. Tubules are in varying stages of regeneration. Some contain pigment casts. There is well marked interstitial oedema. Haematoxylin and eosin $\times 90$.

Fig 5 Regeneration taking place in tubular epithelium. A mitosis is present in the upper half of the photograph. The tubule below the mitotic figure is showing tubulorrhexis. Haematoxylin and eosin $\times 270$.

light microscope sections in the early stages often shows the lining cells to have lost their nuclei (fig 4) and there is also a dissolution of the brush border. These are difficult changes to assess at necropsy as postmortem autolysis affects these cells in a similar manner very soon after death. After three or four days the tubules appear dilated and lined by flattened epithelial cells possessing hyperchromatic nuclei and basophilic cytoplasm. Mitoses can occasionally be seen (fig 5) and the appearances are thought to represent regeneration. A hydropic change is often present in the epithelium even without loss of nuclei (fig 2). The significance of this is in some doubt. Brun and Munck (1957) thought that the change was due to the administration of dextran but there is the possibility that it might represent potassium deficiency. The lumen of the tubules may contain eosinophilic granular material similar to that seen in the glomerular capsular space.
The distal convoluted tubule contains pigment casts made up of myoglobin or haemoglobin (fig 4). These tubules are frequently dilated, lined by flattened epithelial cells and show focal areas of necrosis by three days. Later regeneration with occasional mitotic figures may be seen. Bywaters and Dible (1942) drew attention to these pigment casts which they thought were of considerable functional significance and noted that sometimes they were extruded into the surrounding connective tissues exciting a histiocytic reaction.

The descending and ascending limbs of the nephron together with Henlés loop may all contain casts and show focal areas of necrosis. Polymorphs may be prominent in the collecting tubules.

\section{ELECTRON MICROSCOPE STUDIES ON THE} TUB ULES

Dalgaard and Pedersen (1961), while stating that no changes could be seen in the glomeruli, did note 
extensive changes in the tubules. They emphasized the focal nature of the lesions with normal cells being present alongside the necrotic ones. In studying the kidney in five cases with biopsies taken four to 14 days after the initial shock they showed two main types of lesion.

\section{Degeneration and necrobiosis}

These changes were noted to be focally distributed throughout the nephron. The mitochondria were the most sensitive cellular elements, becoming at first slightly swollen followed by a granulation of the ground substance between the cristae and finally showing complete rupture of the cristae and vacuolation of the ground substance. In some instances, the cells showed complete disintegration with nuclear dissolution and loss of basement membrane and brush border. Similar lesions are present in experimental animals with tubular necrosis (fig 6).

\section{Regeneration and differentiation}

In many of the flattened distal tubular cells there was a high concentration of sulphydryl groups and basophilia in their cytoplasm due to increased RNA; this was considered as evidence of regeneration. A relatively undifferentiated cytoplasm, with cell membranes which were simple in contour, was seen on electron microscopy.

Olsen (1967) examined renal biopsy specimens from 10 patients with acute renal insufficiency which occurred as a complication following surgery, obstetrical procedures, extensive wounds, or caused by poisoning with sulphonamide or barbiturate. In several instances the proximal tubules showed 'osmotic' lesions similar to those seen in experimental animals following infusions of hyperosmotic solutions or dextran. Apart from this there was only a slight degree of damage in the proximal tubules. The 'osmotic' changes consisted of several large cytoplasmic vacuoles, some with dense inclusions. These are in fact degenerate mitochondria. The vacuole membranes had ruptured in some instances. The distal tubules showed a moderate degree of cytoplasmic change but actual necrosis was rare and he considered that the term tubular necrosis should be abandoned. In interpreting these findings it is important to remember that regeneration of tubular epithelium can take place very rapidly, although functional recovery may take much longer, and in the absence of serial biopsies taken from the time of injury to the time of recovery it cannot be denied that necrosis has occurred. Also the tubular damage may be focal and thus not sampled in occasional ultrathin sections.
BOUNDARY ZONE

One of the most characteristic morphological features of the kidney in shock is the accumulation of mononuclear cells seen in the vasa recta at the corticomedullary junction (fig 7). These were first described in patients dying of scrub typhus by Allen and Spitz (1945) but were also noted by Liebow, Warren, and DeCoursey (1949) in those dying following the atom bomb explosions at Hiroshima and Nagasaki. These authors considered the cells to be lymphocytes. Dible (1953) remarked on their resemblance to haemopoietic cells and this observation was confirmed by a careful investigation made by Baker (1958) employing Romanovsky stained films made from blood oozing from the boundary zone as well as conventional histological sections. He considered that the reduction in blood flow was greatest in the medullary blood vessels in shock producing a relative anoxia. The anoxia was thought to be the stimulus for haemopoiesis.

INTERSTITIAL TISSUE

Oedema is often the most notable feature and has been of such prominence as to be invoked as a major factor in the production of anuria (vide infra). Cellular infiltration with lymphocytes and plasma cells is particularly marked in the boundary zone and is often seen in relation to necrosed segments of tubule.

\section{Mechanism of Production of the Renal Lesion}

The causes of tubular necrosis are so many and diverse that probably no one factor is all important in the production of the morphological lesions. In cases of poisoning the main lesions are found at the point in the nephron where the poison becomes fixed to the tubular cell; the most obvious example is the necrosis that is seen in the proximal tubules following ingestion of mercuric chloride. In many instances renal ischaemia must play the most significant role. Badenoch and Darmady (1947) drew attention to the importance of this in an experimental study in rabbits, and Bull, Joekes, and Lowe (1950) have shown diminished renal blood flow in human subjects with anuria following shock. Sirota (1949) demonstrated similar changes in carbon tetrachloride poisoning. These findings correlate well with the ischaemic glomeruli noted by many observers when viewing light microscope sections of the kidney. The presence of intrarenal shunts as an important cause of the lesions (Trueta, Barclay, Daniel, Franklin, and Prichard, 1947) has been doubted by Shaldon, Silva, Lawson, and Walker (1963) who measured the transit time of red cells 


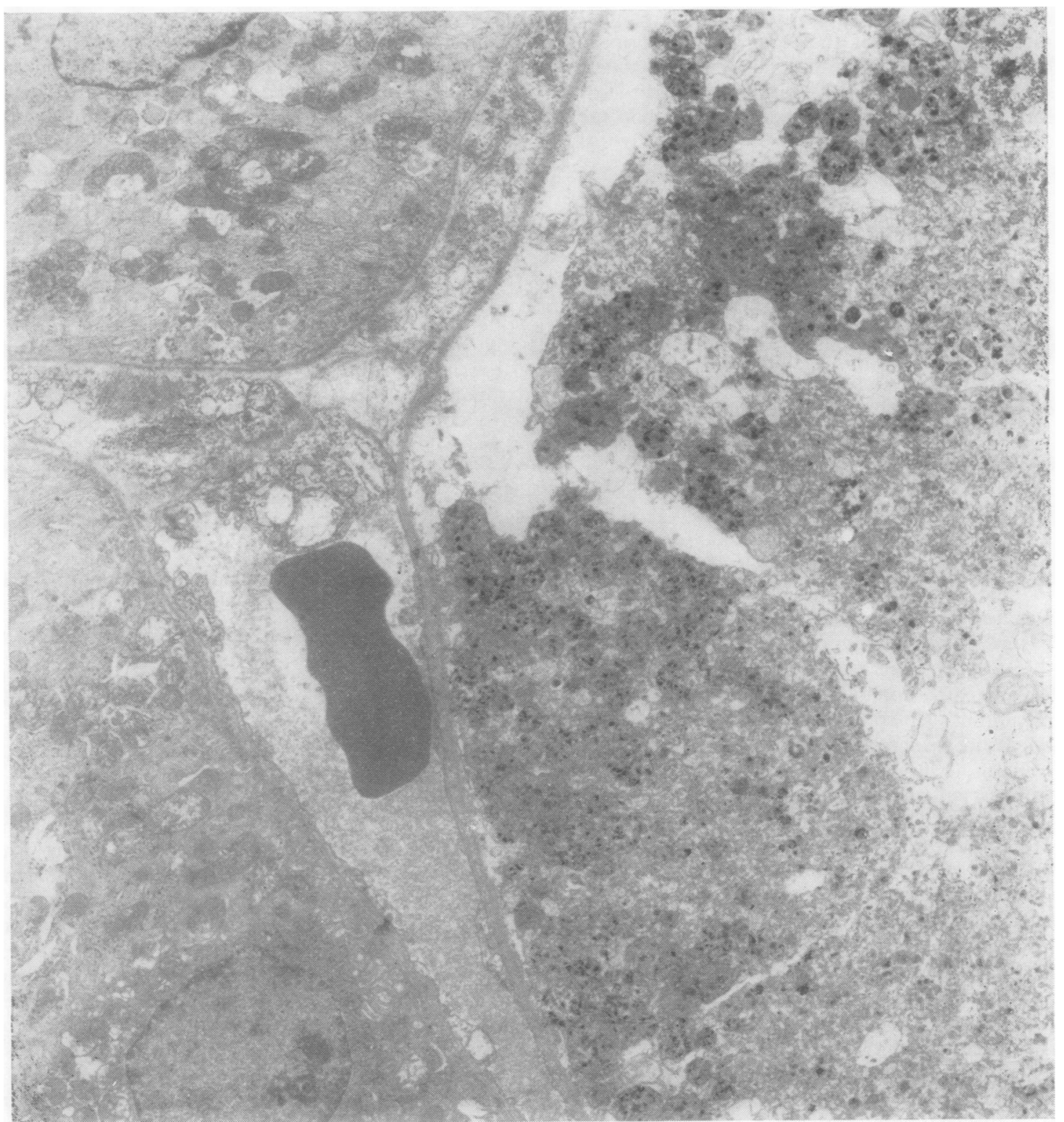

Fig 6 (a) Necrotic proximal tubule in an anuric rat following administration of mercuric chloride. Mitochondria in $\overbrace{\omega}$ varying stages of dissolution can be seen. A peritubular capillary is immediately adjacent to the necrotic cells and two $\underset{<}{\sigma}$ unaffected tubules can be seen. $E M \times 6000$.

labelled with ${ }^{51} \mathrm{Cr}$ through the kidney. Their findings were more in keeping with a red cell shunt occurring at a postglomerular rather than at a medullary level. Fibrinogenopenia has been noted in many cases of shock, particularly of an obstetric origin, and the role of disseminated intravascular coagulation may be of the greatest importance (Wardle, 1973) as may be activation of the renin angiotensin system which? is discussed below.

\section{Mechanism of Production of Anuria}

It is one of the paradoxes of renal pathophysiology that a lesion whose main morphological stigmata 


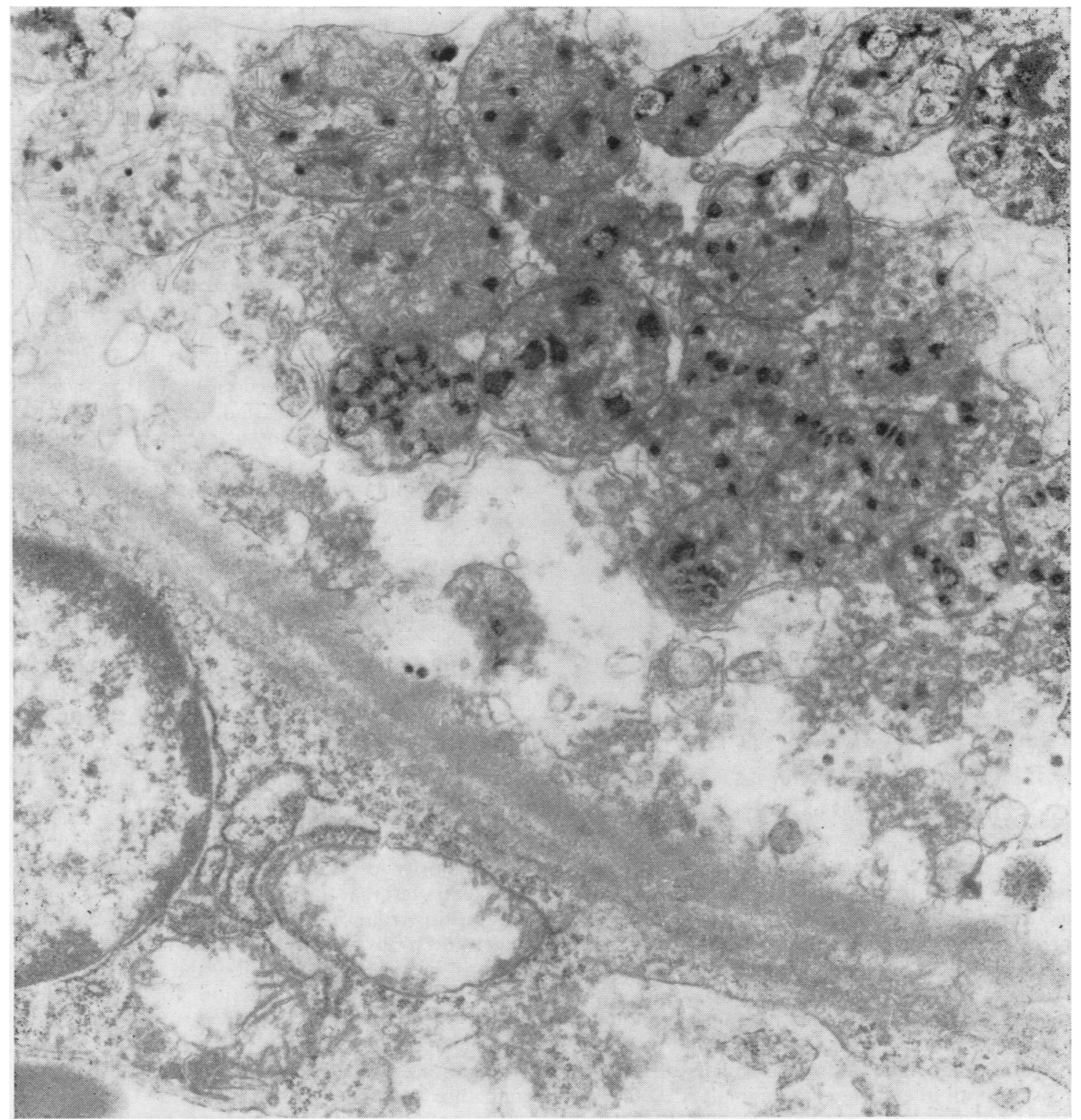

Fig. $6(b)$ High-power view of mitochondria from tubule shown in (a). The dense black mercury particles are situated in the mitochondria often attached to the cristae. EM $\times 22800$.

affect the renal tubules should result in oliguria or anuria. Normally the tubules are concerned with concentrating the urine and it would be logical to suppose that severe damage to them would result in polyuria rather than anuria, particularly as many light microscope studies proclaim that the glomeruli are normal. Several explanations have been put forward to account for the clinical features.
One of the first experimental observations was made by Richards (1929) who used a micro-puncture technique on frogs' kidneys damaged by mercuric chloride. He found that glomerular filtration continued but the animals were anuric and claimed that all the glomerular filtrate must be reabsorbed. He thought that reabsorption occurred into the renal venules by osmosis. In the human kidney which was 


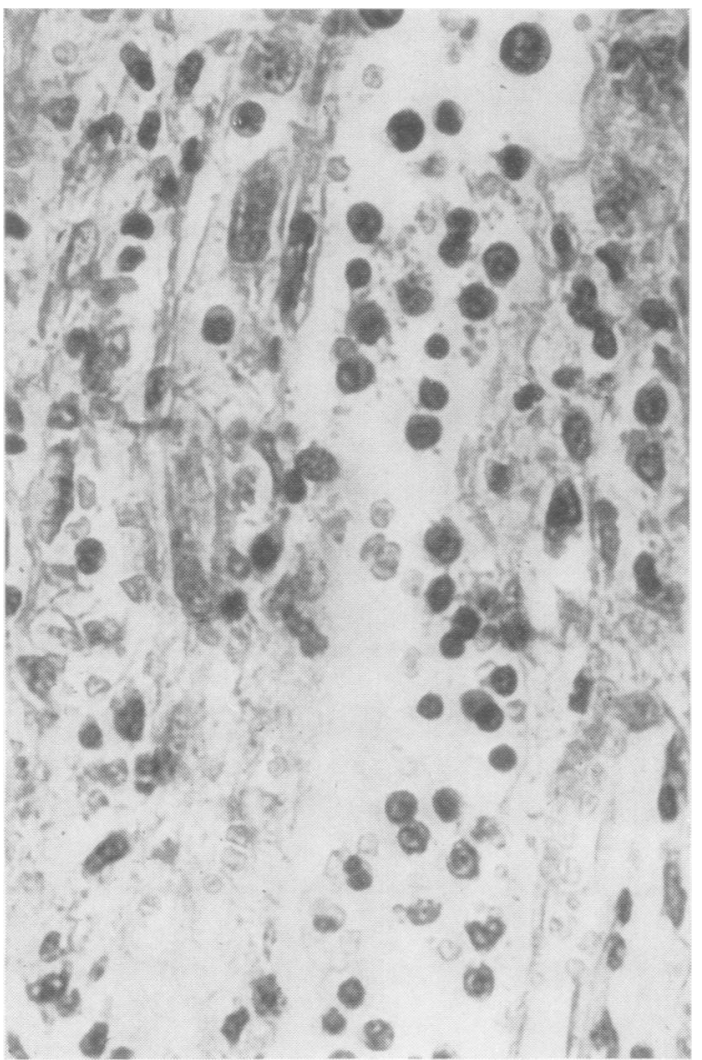

Fig 7 Haemopoietic cells situated in the boundary zone. Haematoxylin and eosin $\times 270$.

the seat of tubular necrosis Dible and Bull (1953), as well as others, put forward the theory that leakage of glomerular filtrate occurred through the damaged tubule into the interstitial tissue with a consequent rise in intrarenal tension. This in turn was considered to cause obstruction to renal blood flow followed by a reduction in glomerular filtration and consequent oliguria. Unfortunately measurements of intrarenal tension both in experimental animals (de Wardener, 1955) and in man (Brun, Crone, Davidson, Fabricius, Hansen, Lassen, and Munck, 1956) have shown no significant difference in intrarenal pressures between normal kidneys and those with anuria due to tubular necrosis.

Mechanical obstruction of the tubules by casts or by swollen tubular cells (Hamburger, Halpern, and Funck-Brentano, 1954) has been invoked as a cause of the anuria. This is certainly not so, as when recovery occurs the casts are removed and provide no obstruction to urine flow. Furthermore there is no evidence of dilatation of those parts of the nephron proximal to the casts or the swollen tubular cells as would be expected if they were in fact causing obstruction.

Sevitt (1959) put forward a series of cogent arguments against the theory that oliguria and uraemia were related to back diffusion of the glomerular filtrate through the tubules. He showed that tubular necrosis was more common than renal failure in patients at risk and also that uraemia could appear following trauma without tubular necrosis. He considered that renal failure was precipitated and maintained by a low glomerular filtration rate resulting from renal ischaemia. Some experimental work has tended to support this view though Sims, Goldberg, Kelly, and Sisco (1959) claimed that in tubular necrosis produced in rats by mercuric chloride the anuria was not dependent upon a critical reduction in glomerular perfusion, and that recovery and diuresis could take place without such a change in perfusion. They assessed glomerular perfusion by injecting the fluorescent dye Thioflavin $S$ and counted the number of glomeruli showing fluorescence, a procedure which might be open to the criticism that it was not performed under truly physiological conditions. However, it may be that the type of lesion produced by mercuric chloride may differ from the lesion produced in the shock kidney. The clinico-pathological study of Finckh, Jeremy, and Whyte (1962) supported the opinion that oliguric renal failure is the result of diminished renal blood flow and reduction in glomerular filtration rate. These authors noted a complete lack of correlation between the clinical features and the lesions seen in the tubules. They considered that the majority of the tubular lesions were due to ischaemia but that the formation of casts was related to the slow rate of glomerular filtration, especially when there was a heavy pigment load, and that the lesions in the distal tubules and the interstitial inflammation were a reaction to the impacted casts.

The importance of the reduction in glomerular filtration has gained strong support from the micropuncture work of Flanigan and Oken (1965) studying oliguria produced in rats by intramuscular injection of mercuric chloride. They claimed to demonstrate that there was a progressive reduction in glomerular filtration rate and that tubular obstruction due to cast formation or interstitial oedema together with passive backflow of filtrate played no part in the development of anuria. Similar results were obtained by Oken, Arce, and Wilson (1966) in rats rendered oliguric by intramuscular injection of $50 \%$ glycerol in water. They postulated that the reduced glomerular filtration rate was consequent upon an alteration in the afferent-efferent arteriolar tone possibly related to 
changes in the renin-angiotensin systems. However, micropuncture techniques in the mammalian kidney are by no means as simple as in the frog's kidney and it may be doubted whether their observations are a true reflection of the conditions in vivo.

The role of the renin-angiotensin system in the initial cortical and glomerular ischaemia following some forms of shock may be of great importance (Henry, Lane, and Kashgarian, 1968; Brown, Gleadle, Lawson, Lever, Linton, MacAdam, Prentice, Robertson, and Tree, 1970). The hypotension occurring in shock causes a release of renin into the blood from the kidney with the formation of angiotensin I and II. Angiotensin II in turn causes preglomerular arteriolar constriction and thus decreased glomerular filtration. Henry et al (1968), using a rat experimental model with subcutaneous injection of potassium dichromate, found that proximal tubular necrosis occurred in sodium-depleted animals and not in salt-loaded animals. This may be of importance in explaining the variability of the degree of renal damage in different patients in the same or similar clinical situations. It is not clear how the reninangiotensin system is activated in cases where there is no severe hypotension as the initial insult and furthermore it does little to explain the prolonged oliguria or anuria that occurs even after the blood pressure has returned to normal limits.

The functional evidence of the glomerular origin of the oliguria makes it all the more extraordinary that more attention has not been paid to the glomeruli by pathologists. However, Sevitt (1959) did describe an exudate in the capsular space together with multiple lipid droplets in the glomerular epithelium. This deficiency in histological knowledge has to some extent been rectified by the work of Olsen and Skjoldborg (1967) and of Clarkson et al (1970). The latter study, which found deposits of fibrin and platelets consistent with intraglomerular capillary thrombosis, was carried out in conjunction with serial studies of coagulation and fibrinolysis and showed abnormalities to be present in the oliguric phase with elevation of the fibrin-fibrinogen degradation products, plasma fibrinogen, soluble fibrin monomer complexes, and platelet factor 4. Recovery of renal function was associated with resolution of the intraglomerular coagulation, correction of coagulation abnormalities, and excretion of large quantities of fibrin-fibrinogen degradation products in the urine.

Clarkson et al (1970) considered that the obstruction of the glomerular capillaries by fibrinplatelet aggregates could be a major factor in the oliguria. While these aggregates may play a part in the suppression of urine production it is by no means certain that it is an all-important one. In any electron microscope study it must be remembered that only a very few glomeruli are sampled and it cannot be assumed that appearances seen in these are a true reflection of the state of affairs in all the glomeruli in the kidney.

One of the most fundamental objections to the theory that lack of glomerular filtration is the prime cause of the anuria, however, is based on radiological evidence. Intravenous urography was performed by Chamberlain and Sherwood $(1966,1967)$ in an experimental study of acute renal failure in the rat induced either by temporary renal ischaemia or by intraperitoneal injection of mercuric chloride. All the animals were azotaemic though urine output ranged from polyuria to anuria but a dense nephrogram was always obtained even in animals with complete anuria. It was concluded that glomerular filtration was occurring. These findings supported the work of Sims et al (1959). Furthermore Bank, Mutz, and Aynedjian (1967), using a micropuncture technique on rats with anuria due to mercuric chloride administration, demonstrated glomerular filtration to be taking place at a normal rate. They also injected intravenously lissamine green in the early stages of anuria and showed that the dye appeared in the first part of the proximal tubule but that it was barely visible in the terminal parts of the proximal tubule and did not appear at all in the distal tubule, suggesting that the proximal tubular epithelium had become abnormally permeable to the dye and to the glomerular filtrate, with resultant oliguria.

Early observations on angiography in acute renal failure in human subjects by Shaldon et al (1964) failed to demonstrate a nephrogram after injection of diatrizoate into the renal artery, but only a single five-second exposure was given and this may well have been too early to demonstrate the nephrogram. The whole subject of the nephrogram in acute tubular necrosis has recently been reviewed by Fry and Cattell (1972) and they show in a convincing manner that a dense nephrogram occurs in patients with acute tubular necrosis and, in contrast to normal subjects, it persists unchanged for hours or days. Since the nephrogram depends on the contrast medium being filtered by the glomerulus and being present in the tubules these observations favour the 'back diffusion' theory for explaining the oliguria and it now seems most likely that in many, and indeed most, cases of the 'shock kidney' the oliguria is due to the complete reabsorption of the glomerular filtrate into the renal venules through the damaged proximal tubular epithelium and is probably dependent on an osmotic effect. It is difficult to account for the radiological observations in both human subjects and experimental animals 
in any other manner. The exact relationship between the histological findings and the functional performance of the kidney remains difficult to elucidate. As has already been stated, in many cases the tubules do not appear completely necrotic and it is obvious that severe functional derangement can occur without total cellular death. It is, however, likely that at some stage many cells do die and regeneration takes place but not necessarily accompanied by functional recovery. In this connexion a case report by Morrin, Gedney, Barth, and Heptinstall (1962) is of great interest in that a patient who suffered acute tubular necrosis secondary to carbon tetrachloride inhalation survived 67 days of oliguria with a urinary output never exceeding $350 \mathrm{ml}$ per 24 hours. In this case renal biopsies were performed on the 38th and 64th days and showed normal glomeruli and regenerating tubular epithelium but in spite of this histological evidence of recovery the clinical course was a relentless one of persistent oliguria and the patient died.

\section{Summary}

The pathological findings and the pathogenesis of the oliguria in acute renal failure (acute tubular necrosis) are disputed by many pathologists and physicians. In assessing the histological features it is essential to realize that these alter with time and that some instances where no necrosis has been found in the tubular epithelium may be due to the biopsy, or necropsy, material having been taken after regeneration has started to take place. Also the tubular lesions may often be focal and so missed unless numerous sections are examined or special techniques, eg, microdissection of nephrons, are used. Finally tubules which are regenerating, or on light microscopy appear to have regenerated, may still show profound functional abnormalities.

The ultrastructural glomerular changes which have been described by some authors must be viewed with caution when invoked as an explanation for the oliguria, as here sampling is of the greatest importance. It must not be assumed that changes seen in a few, or even all, the capillaries in one glomerulus are present throughout all the glomeruli in such quantity as to cause functional disturbance.

Ischaemia, mediated through the renin-angiotensin system, is probably of considerable importance in the initial fa'l in glomerular filtration and in the ischaemic element in the causation of cell necrosis in the tubules. It does not however provide an adequate explanation for the oliguria once the blood pressure has returned to normal. Radiological evidence, in the form of dense persistent nephrograms, as well as some animal experimental studies, strongly suggest that back diffusion of glomerular filtrate, originally proposed by Richards in 1929, is an important factor in the pathogenesis of prolonged oliguria.

I am grateful to Mr Dennis Jerrome for assistance with the electron micrographs.

\section{References}

Allen, A. C., and Spitz, S. (1945). A comparative study of the pathology of scrubtyphus (Tsutsugamushi disease) and other rickettsial diseases. Amer. J. Path., 21, 603-681.

Badenoch, A. W., and Darmady, E. M. (1947). The effects of temporary occlusion of the renal artery in rabbits and its relationship to traumatic uraemia. J. Path. Bact., 59, 79-94.

Baker, S. B. de C. (1958). Intravascular haemopoiesis in the renal medulla in shock. J. Path. Bact., 75, 421-428.

Bank, N., Mutz, B. F., and Aynedjian, H. S. (1967). The role of 'leakage' of tubular fluid in anuria due to mercury poisoning. J. clin. Invest.. 46, 695-704.

Briggs, J. D., Kennedy, A. C., Young, L. N., Luke, R. G., and Gray, M. (1967). Renal function after acute tubular necrosis. Brit. med. J., 3, 513-516.

Brown, J. J., Gleadle, R. I., Lawson, D. H., Lever, A. F., Linton, A. L., MacAdam, R. F., Prentice, E., Robertson, J. I. S., and Tree, M. (1970). Renin and acute renal failure: studies in man. Brit. med. J., 1, 253-258.

Brun, C., Crone, C., Davidsen, H. G., Fabricius, J., Hansen, A. T., Lassen, N. A., and Munck, O. (1956). Renal interstitial pressure in normal and in anuric man: based on wedged vein pressure. Proc. Soc. exp. Biol. (N.Y.), 91, 199-202.

Brun, C., and Munck, O. (1957). Lesions of the kidney in acute renal failure following shock. Lancet, 1, 603-607.

Bull, G. M., Joekes, A. M., and Lowe, K. G. (1950). Renal function studies in acute tubular necrosis. Clin. Sci., 9, 379-404.

Bywaters, E. G. L., and Dible, J. H. (1942). The renal lesion in traumatic anuria. J. Path. Bact., 54, 111-120.

Chamberlain, M. J., and Sherwood, T. (1966). The extra renal excretion of diatrizoate in renal failure. Brit. J. Radiol., 39, 765-770.

Chamberlain, M. J., and Sherwood, T. (1967). Intravenous urography in experimental renal failure in rat. Nephron, 4, 65-74.

Clarkson, A. R., MacDonald, M. K., Fuster, V., Cash, J. D., and Robson, J. S. (1970). Glomerular coagulation in acute ischaemic renal failure. Quart. J. Med., 39, 585-599.

Dalgaard, O. Z. (1960). An electron microscopic study on glomeruli in renal biopsies taken from human shock kidney. Lab. Invest., 9, 364-366.

Dalgaard, O. Z., and Pedersen, K. J. (1961). Ultrastructure of the kidney in shock. In Proceedings of the Ist Internationcl Congress on Nephrology, edited by G. Richet, pp. 165-176. Karger, Basle and New York.

Dible, J. H. (1953). In Recent Advances in Pathology, 6th ed., edited by G. Hadfield, p. 291. Churchill, London.

Dible, J. H., and Bull, G. M. (1953). In Recent Advances in Pothology, 6th ed., edited by G. Hadfield, p. 302. Churchill, London.

Dunn. J. S., Gillespie, M., and Niven, J. S. F. (1941). Renal lesions in two cases of crush syndrome. Lancet, 2, 549-552.

Finckh, E. S., Jeremy, D., and Whyte, H. M. (1962). Structural renal damage and its relation to clinical features in acute oliguric renal failure. Quart. J. Med., 31, 429-446.

Flanigan, W. J., and Oken, D. E. (1965). Renal micropuncture study of the development of anuria in the rat with mercury-induced acute renal failure. J. clin. Invest., 44, 449-457.

Fry, I. K., and Cattell, W. R. (1972). The nephrographic pattern during excretion urography. Brit. med. Bull., 28, 227-232.

Hamburger, J., Halpern, B., and Funck-Brentano, J. L. (1954). Une variété d'anurie provoquée par l'hydration excessive des cellules rénales. Presse méd., 62, 972-976.

Hamburger, J., Richet, G., Crosnier, J., Funck-Brentano, J. L., Antoine, B., Ducrot, H., Mery, J. P., and Montera, H. de (1968). Nephrology, p. 503. Saunders, Philadelphia and London.

Henry, L. N., Lane, C. E., and Kashgarian, M. (1968). Micropuncture studies of the pathophysiology of acute renal failure in the rat. Lab. Invest., 19, 309-314.

Heptinstall, R. H. (1966). The Pathology lof the Kidney, p. 650. Churchill, L ondon. 
Kennedy, A. C., Burton, J. A., Luke, R. G., Briggs, J. D., Lindsay, R. M., Allison, M. E. M., Edward, N., and Dargie, H. J. (1973). Factors affecting the prognosis in acute renal failure. Quart. J. Med., 42, 73-86.

Liebow, A. A., Warren, S., and DeCoursey, E. (1949). Pathology of atomic bomb casualties. Amer. J. Path., 25, 853-1027.

Lucke, B. (1946). Lower nephron nephrosis: the renal lesions of the crush syndrome, of burns, transfusions and other conditions affecting the lower segments of the nephrons. Milit. Surgn, 99, 371-396.

Morrin, P. A. F., Gedney, W. B., Barth, W., and Heptinstall, R. H. (1962). Acute tubular necrosis: report of a case with failure to recover after sixty-seven days of oliguria. Ann. intern. Med., 56, 925-930.

Oken, D. E., Arce, M. L., and Wilson, D. R. (1966). Glycerolinduced hemoglobinuric acute renal failure in the rat. $I$. Micropuncture study of the development of oliguria. J. clin. Invest., 45, 724-735.

Oliver, J., MacDowell, M., and Tracy, A. (1951). The pathogenesis of acute renal failure associated with traumatic and toxic injury: renal ischemia, nephrotoxic damage and the ischemuric episode. J. clin. Invest., 30, 1307-1439.

Olsen, T. S. (1967). Ultrastructure of the renal tubules in acute renal insufficiency. Acta path. microbiol. scand., 71, 203-218.

Olsen, T. S., and Skjoldborg, H. (1967). The fine structure of the renal glomerulus in acute anuria. Acta path. microbiol. scand., 70, 205-214.

Richards, A. N. (1929). Direct observations of change in function of renal tubule caused by certain poisons. Trans. Ass. Amer. Phycns. 44, 64-67.
Schmidt, P. J.. and Holland, P. V. (1967). Pathogenesis of the acute renal failure associated with incompatible transfusion. Lancet, 2, 1169-1172.

Sevitt, S. (1959). Pathogenesis of traumatic uraemia. Lancet, 2, $135-141$.

Shaldon, S., Sheville, E., and Rae, A. I. (1964). Angiography in acute renal failure. Clin. Radiol., 15, 123-129.

Shaldon, S., Silva, H., Lawson, T. R., and Walker, J. G. (1963). Measurement of renal red cell and plasma transit times in acute renal failure. Proc. Soc. exp. Biol. (N.Y.), 112, 359-362.

Sims, E. A. H., Goldberg, H. I., Kelly, J. R., and Sisco, B. (1959). Glomerular perfusion during acute renal insufficiency from mercury poisoning in the rat. J. Lab. clin. Med., 54, 440-449.

Sirota, J. H. (1949). Carbon tetrachloride poisoning in man: I. The mechanisms of renal failure and recovery. J. clin. Invest., 28, 1412-1422.

Teschan, P. E., Post, R. S., Smith, L. H., Jr., Abernathy, R. S., Davis, J. H., Gray, D. M., Howard, J. M., Johnson, K. E., Klopp, E., Mundy, R. L., O'Meara, M. P., and Rush, B. F., Jr. (1955). Post-traumatic renal insufficiency in military casualties. Amer. J. Med., 18, 172-186.

Trueta, J., Barclay, A. E., Daniel, P. M., Franklin, K. J., and Prichard, M. M. L. (1947). Studies of the Renal Circulation. Oxford, Blackwell.

Wardener, H. E. de (1955). Intrarenal pressure in experimental tubular necrosis. Loncet, 1, 580-584.

Wardle, E. N. (1973). Fibrinogen catabolism studies in patients with renal disease. Quart. J. Med., 42, 205-219.

Waugh, D., Schlieter,. W., and James, A. W. (1964). Infraglomerular epithelial reflux Arch. Path., 77, 93-96. 